\title{
Developmental Studies on the Presphenoid in the Human Sphenoid Bone
}

\author{
by \\ George Kodama \\ The Second Department of Anatomy \\ Hokkaido University School of Medicine \\ Sapporo, Japan \\ (Director: Prof. Dr. S. I t o)
}

Up to the present, a number of developmental studies on the presphenoid in the human sphenoid bone have been reported (A. H a n nover, 1880 ; C. Toldt, 1882 ; J. B. S utton, 1885 ; Ph. C. Sappey, 1888 ; F. Keibel u. F. P. Mall, 1910 ; Lawrence, 1928 ; R. G. I n k s ter, 1951 etc.). However, the majority of these descriptions are extremely simple. In the present investigation an attempt was made to execute developmental studies on the presphenoid in the human sphenoid bones.

\section{Materials and Methods}

Specimens are comprised of 60 dehydrated skulls of embryos and 10 macerated skulls of embryos and 4 macerated skulls of infants. Specimens of the dehydrated skulls of the embryos immediately after clinical abortion were prepared by the following methods; materials used were the skulls of embryos ranging from $14.0 \mathrm{~cm}$ to $40.0 \mathrm{~cm}$ from which brain matter was already removed. First the abovementioned materials were soaked in water for one or two days, then the periosteum and the dura mater were ablated in order to observe the presphenoid and also to prevent the skulls from curling up innerwards, after which the materials were dehydrated by exposure to air. The merits of the specimens thus prepared are that even the smaller ossific centers may be observed without a possibility of disappearance, and that the ossific centers are ready for reexamination when the specimens are placed in water or alcohol to obtain fresh conditions. In embryos larger than $41.0 \mathrm{~cm}$ in height, that is to say, embryos of the 9th and the 10th foetal month and also in infants, the macerated skulls are ideal to be studied, for in 
these cases the ossific centers remain intact owing to the complete unions between the ossific centers of the presphenoid and the other ossific centers.

\section{Observations}

The number of ossific centers of the presphenoid were identical as 5 types, a total of 9 pieces in the present observation.

A pair of main centers (1 in Fig. 1) which have been described as "presphenoid" by a number of workers appear near the crus posterior of the orbitosphenoid. The orbitosphenoid was formerly divided into 2 parts, crus anterior and crus posterior, by the present writer in 1964.

A pair of anterior, accessory centers (2 in Fig. 1) appear on the upper root which comes from the crus anterior of the orbitosphenoid. These are located in a slightly forward position from the main centers.

A pair of posterior, accessory centers (3 in Fig. 1) appear at the posterior, lateral end of the main centers.

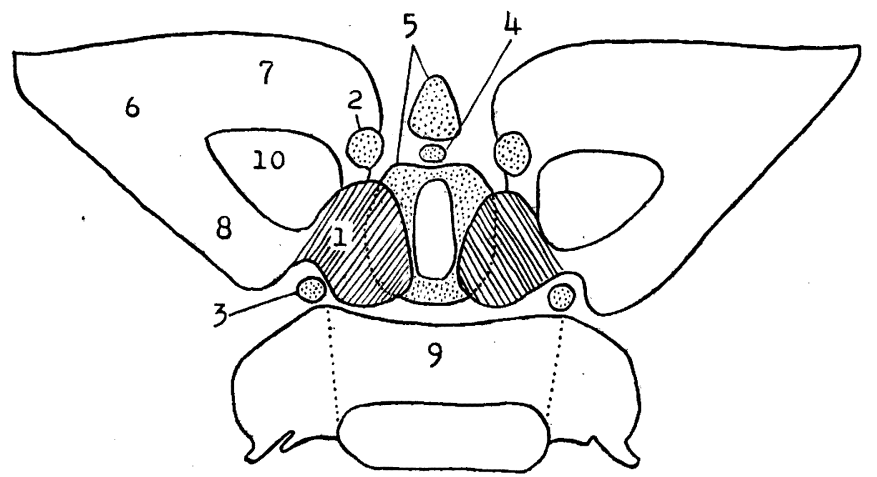

The Presphenoid

1 -the main center

2 -the anterior, accessory center

3 -the posterior, accessory center

4 -the middle, accessory center

5 -the corporal, middle center

Others

6-the orbitosphenoid

7 -the crus anterior of the orbitosphenoid

8 -the crus posterior of the orbitosphenoid

9 -the basisphenoid

10-the optic canal

Fig. 1. Types of Ossific Centers of the Presphenoid and Others. 
A piece of the middle, accessory center (4 in Fig. 1) appears on the median line, placed between both sides of the main centers.

Two pieces of the corporal, middle centers (5 in Fig. 1), an anterior center and a posterior center, which are different from the above-mentioned four types of centers which lie in the superficial layer, appear in the profound layer which is separated from the above-mentioned four by a membrane superiorly.

In order to calculate the rates of appearance of the ossific centers of the presphenoid, dehydrated skulls and sphenoid bones of embryos (70 cases) were divided into the following 7 groups in accordance with their body length and foetal month; 14.0-19.0 cm (11 cases), $20.0-23.0 \mathrm{~cm}$ (10 cases), $24.0-25.0 \mathrm{~cm}$ (11 cases), $26.0-28.5 \mathrm{~cm}$ (11 cases), $29.0-31.5 \mathrm{~cm}$ (15 cases), $32.0-40.0 \mathrm{~cm}$ (12 cases), and the 9 th and 10th foetal month (10 cases). Thus the rates of appearance in the ossific centers of the presphenoid were calculated and studied.

1. The main center (Tábles 1 and 2)

Out of the 5 types of the presphenoid ossific centers, the main centers, which have been described as the so-called "presphenoid" by other workers, were the first to make their appearance. The smallest embryo with the main centers was $17.0 \mathrm{~cm}$ in body length. The rates of appearane in the main centers are as follows; 1 case out of $11(14.0-19.0 \mathrm{~cm})(9.09 \pm 8.67 \%), 8$ cases out of $10(20.0-23.0 \mathrm{~cm})$ $(80.00 \pm 12.65 \%), 9$ cases out of $11(24.0-25.0 \mathrm{~cm})(81.82 \pm 11.63 \%), 8$ cases out of $11(26.0-28.5 \mathrm{~cm})(72.73 \pm 13.42 \%), 13$ cases out of 15 $(29.0-31.5 \mathrm{~cm})(86.66 \pm 13.33 \%), 12$ cases out of $12(32.0-40.0 \mathrm{~cm})$ $(100.00 \%$ ) and 10 cases out of 10 (the 9 th and 10 th foetal month) $(100.00 \%)$. In one $29.0 \mathrm{~cm}$ embryo the main centers failed to appear. However, in all other cases larger than $29.5 \mathrm{~cm}$ the main centers were observed.

Table 1. Types of ossfic centers of presphenoid and their appearances.

\begin{tabular}{|c|c|c|}
\hline Types of ossific center & $\begin{array}{c}\text { Length of embryo (cm) } \\
\text { showing the first } \\
\text { appearance of the } \\
\text { ossific center }\end{array}$ & $\begin{array}{c}\text { Length of embryo (cm) } \\
\text { or foetal month of } \\
\text { embryo showing 100\% } \\
\text { appearance of the } \\
\text { ossific center }\end{array}$ \\
\hline $\begin{array}{c}\text { the main center (hitherto } \\
\text { described as presphenoid) } \\
\text { the anterior, accessory center } \\
\text { the posterior, accessory center } \\
\text { the middle, accessory center } \\
\text { the corporal, middle center }\end{array}$ & 18.0 & 29.5 \\
\hline
\end{tabular}


Table 2. Rate of appearance of the main center.

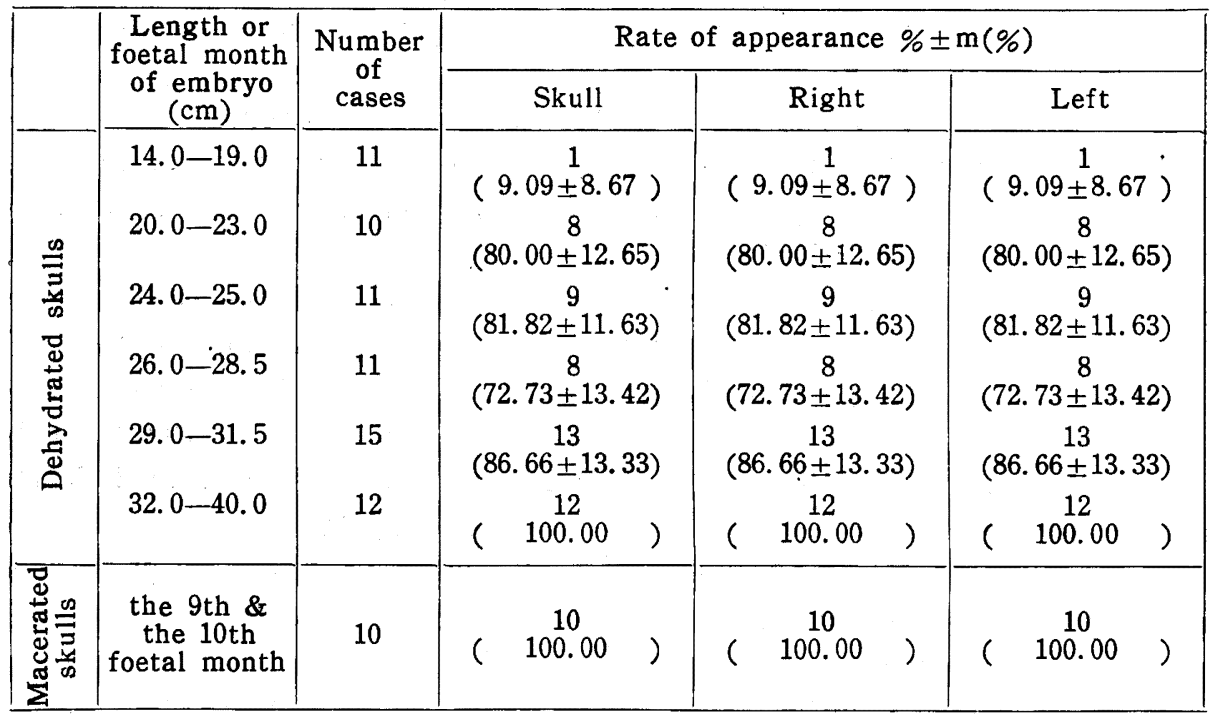

Table 3. Rate of appearance of the anterior, accessory center.

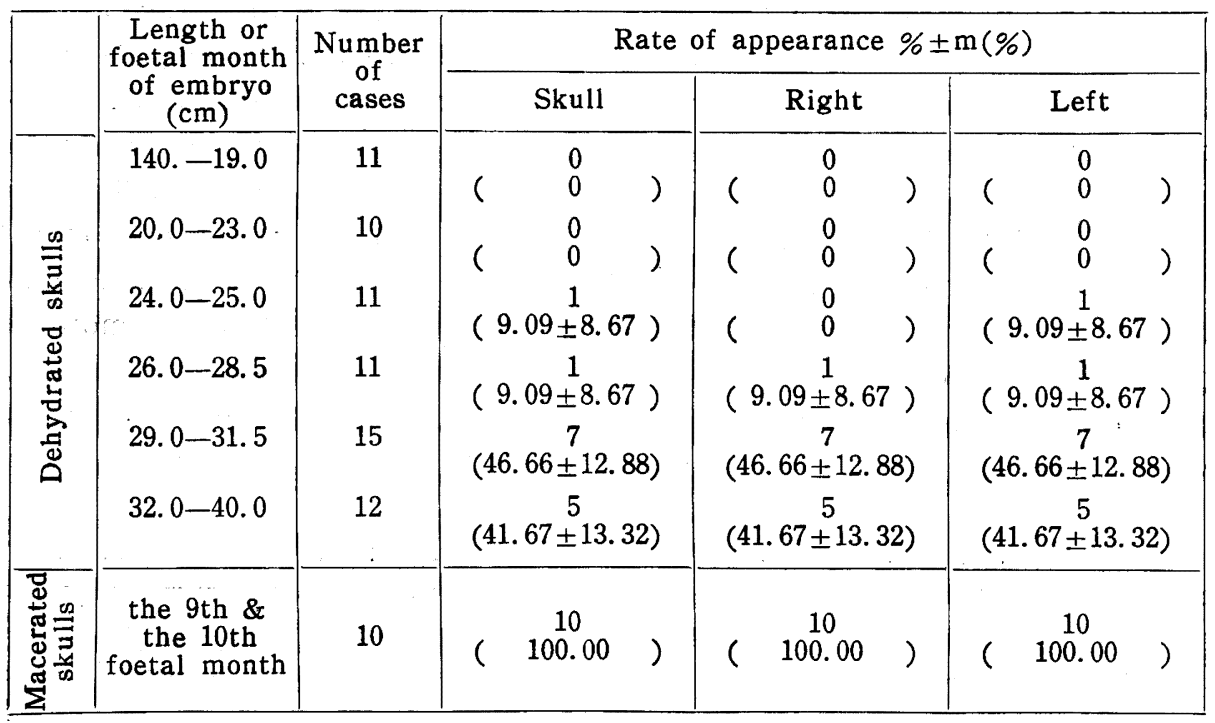

As described above, the time of appearance of the main centers differs, but in general the appearance is almost the same in embryos larger than $20.0 \mathrm{~cm}$. The main centers also vary in size; for instance, in the case of $23.0 \mathrm{~cm}$ embryos, the size is that of a grain of rice in one case, while miliary in size in another case. Occasionally the sizes of the left and right main centers differed; for exam- 
ple, the left was miliary while the right was that of a rice grain.

2. The anterior, accessory centers (Tables 1 and 3 )

The anterior, accessory centers made their first appearance in a $24.5 \mathrm{~cm}$ embryo. The rates of appearance in the anterior, acces-sory centers are as follows; 0 case out of $11(14.0-19.0 \mathrm{~cm})(0 \%), 0$ case out of $10(20.0-23.0 \mathrm{~cm})(0 \%), 1$ case out of $11(24.0-25.0 \mathrm{~cm})$ $(9.09 \pm 8.67 \%), 1$ case out of $11(26.0-28.5 \mathrm{~cm})(9.09 \pm 8.67 \%), 7$ cases out of $15(29.0-31.5 \mathrm{~cm})(46.66 \pm 12.88 \%), 5$ cases out of $12(32.0-40.0$ $\mathrm{cm})(41.67 \pm 13.32 \%)$ and 10 cases out of 10 (the 9 th and 10 th foetal month) (100.00\%). The largest embryo which failed to show an appearance of the anterior, accessory centers had a body length of $40.0 \mathrm{~cm}$. While generally the appearance of these centers are in pairs, in one exceptional case (No. $293,24.5 \mathrm{~cm}$ ) the right side center was missing.

3. The posterior, accessory centers (Tables 1 and 4)

The posterior, accessory centers made their first appearance in a $31.0 \mathrm{~cm}$ embryo. In the cases of the embryos with body lengths under $28.5 \mathrm{~cm}$, not a single case with these types of the ossific centers was observed. Moreover, these centers were observed in only 2 cases out of $15(29.0-31.5 \mathrm{~cm})(13.33 \pm 9.35 \%)$. In addition, in all cases of embryos with body lengths over $32.0 \mathrm{~cm}$ the centers were missing. Hence, it is suggested that the posterior, accessory centers are not completely ossified in the foetal period.

Table 4. Rate of appearance of the posterior, accessory center.

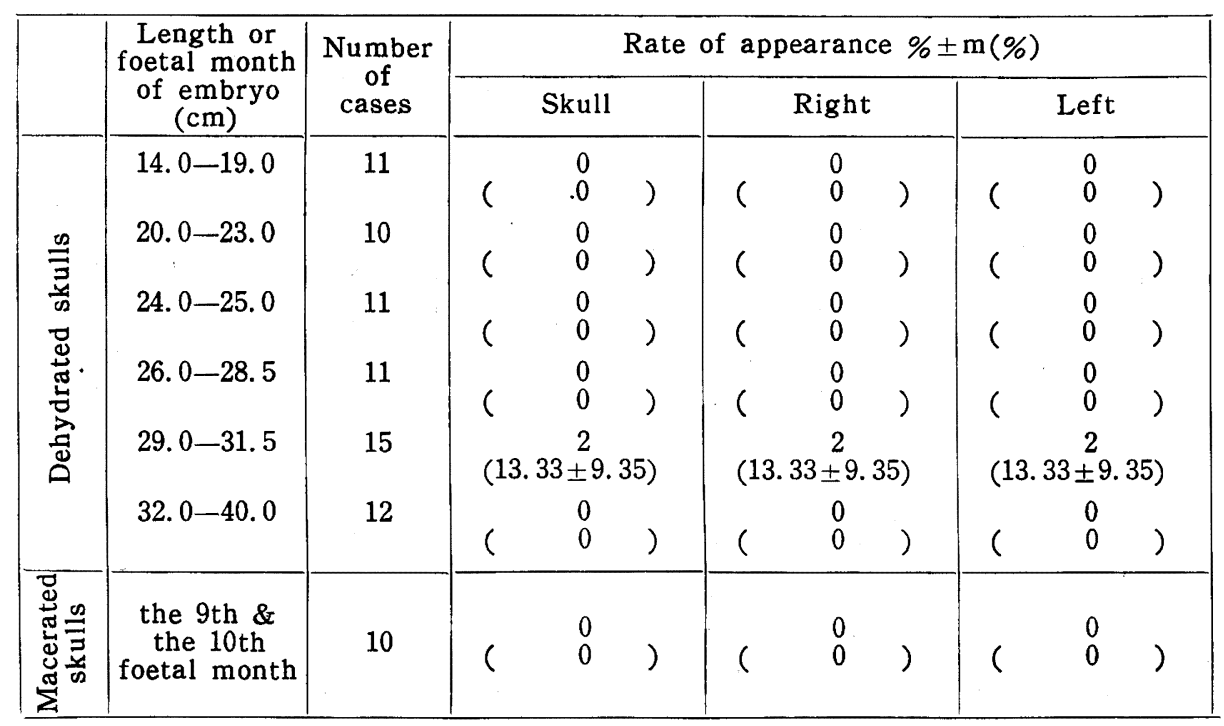


4. The middle, accessory centers (Tables 1 and 5)

The middle, accessory center made its first appearance in a 34.0 $\mathrm{cm}$ embryo. This type of center is rarely ossified in embryos under $31.5 \mathrm{~cm}$. This center was observed in 1 case out of $12(32.0-40.0 \mathrm{~cm})$ $(8.33 \pm 8.47 \%)$ and 3 cases out of 10 (the 9 th and 10 th foetal month) $(30.00 \pm 14.49 \%)$. Therefore, it is suggested that the middle, accessory center makes an imperfect ossification during foetal life as in

Table 5. Rate of appearance of the middle, accessory center.

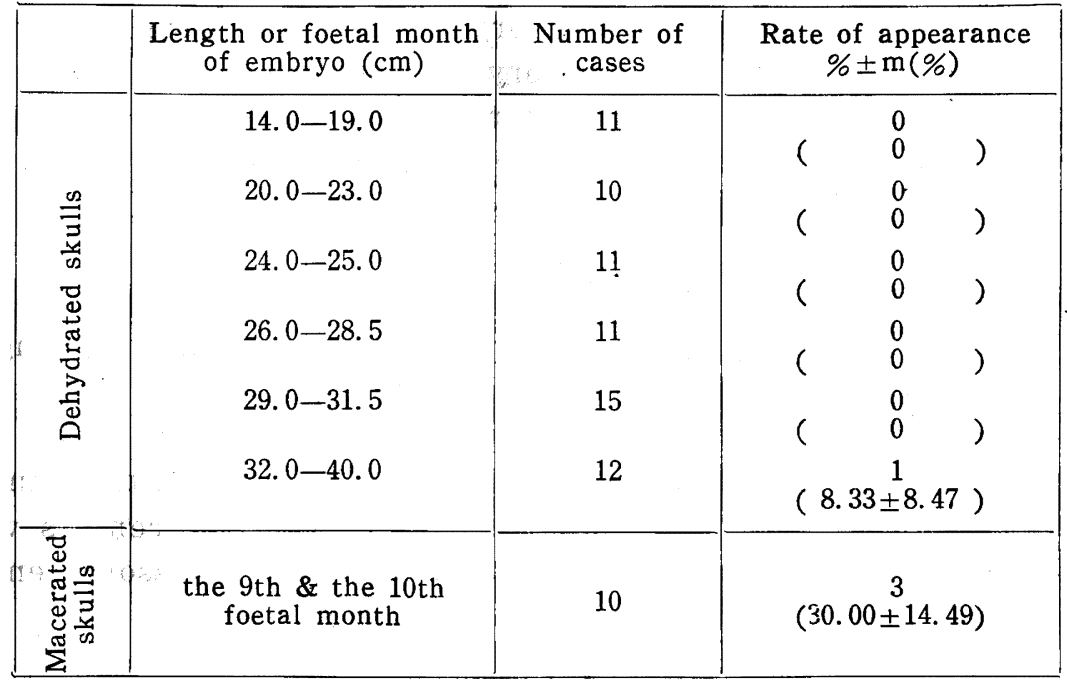

Table 6. Rate of appearance of the corporal middle center.

\begin{tabular}{|c|c|c|c|}
\hline & $\begin{array}{l}\text { Length or foetal month } \\
\text { of embryo }(\mathrm{cm})\end{array}$ & $\begin{array}{c}\text { Number of } \\
\text { cases }\end{array}$ & $\begin{array}{c}\text { Rate of appearance } \\
\% \pm \mathrm{m}(\%)\end{array}$ \\
\hline 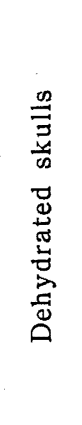 & $\begin{array}{l}14.0-19.0 \\
20.0-23.0 \\
24.0-25.0 \\
26.0-28.5 \\
29.0-31.5 \\
32.0-40.0\end{array}$ & $\begin{array}{l}11 \\
10 \\
11 \\
11 \\
15 \\
12\end{array}$ & 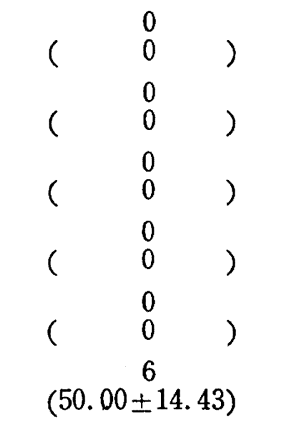 \\
\hline 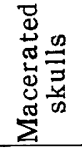 & $\begin{array}{l}\text { the } 9 \text { th } \& \text { the } 10 \text { th } \\
\text { foetal month }\end{array}$ & 10 & $\begin{array}{c}10 \\
(\quad 100.00\end{array}$ \\
\hline
\end{tabular}


the case of the posterior, accessory centers.

5. The corporal, middle centers (Tables 1 and 6)

The corporal, middle centers made their first appearance in a $34.0 \mathrm{~cm}$ embryo. These ossific centers were not observed in embryos under $31.5 \mathrm{~cm}$. These centers appear in 6 cases out of $12(32.0-40.0$ $\mathrm{cm})(50.00 \pm 14.43 \%)$ and 10 cases out of 10 (the 9 th and 10 th foetal month) (100.00\%). Thus, it is understood that these centers gradually appear in accordance with the growth of the embryos.

The unions between the ossific centers of the presphenoid and the other ossific centers were studied and the following results were obtained. (Table 7)

Table 7. Unions between the presphenoid and the other types of ossific centers.

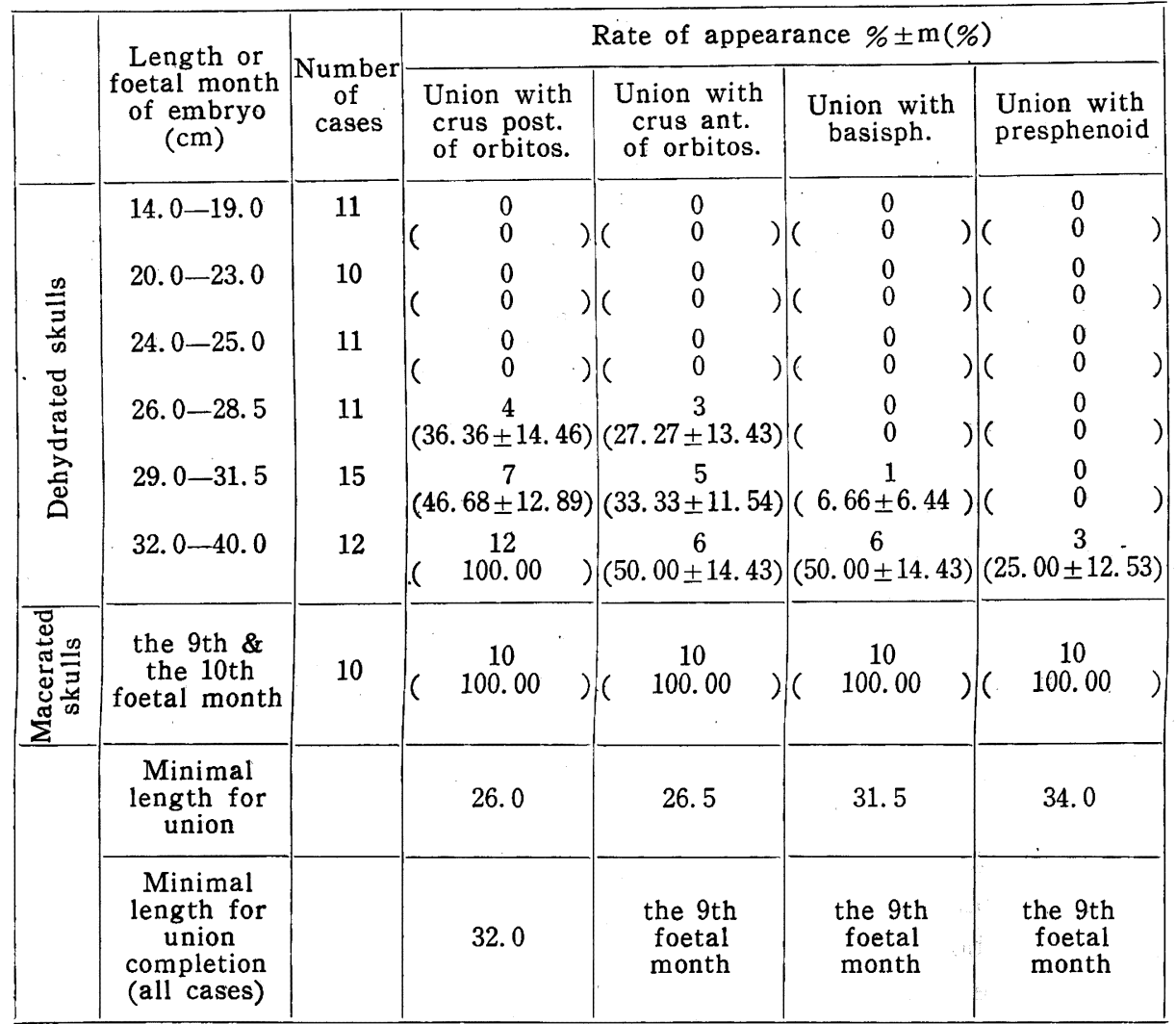

As the embryos grow, the ossific centers of the presphenoid begin to unite with other types of ossific centers in the sphenoid bone, i. e. the orbitosphenoid, the basisphenoid and the counter side 
of the presphenoid.

1. The union with the crus posterior of the orbitosphenoid

The union between the main centers of the presphenoid and the crus posterior of the orbitosphenoid was first observed in an embryo of $20.0 \mathrm{~cm}$. This union was not seen in embryos under 25.0 $\mathrm{cm}$. This union was observed in 4 cases out of $11(26.0-28.5 \mathrm{~cm})$ $(36.36 \pm 14.46 \%), 7$ cases out of $15(29.0-31.5 \mathrm{~cm})(46.68 \pm 12.89 \%)$ and in all cases of the embryos larger than $32.0 \mathrm{~cm}$ in body length. In other words, this union is completed, when the embryo attains 32.0 cm. This union is bilaterally observed in all cases.

2. The union with the crus anterior of the orbitosphenoid

The main center of the presphenoid begins to unite with the crus anterior of the orbitosphenoid in a $26.5 \mathrm{~cm}$ embryo. This union was not seen in any of the embryos under $25.0 \mathrm{~cm}$. However, the union is found in 3 cases out of $11(27.0-28.5 \mathrm{~cm})(27.27 \pm 13.43 \%), 5$ cases out of $15(29.0-31.5 \mathrm{~cm})(33.33 \pm 11.54 \%), 6$ cases out of $12(32.0-$ $40.0 \mathrm{~cm})(50.00 \pm 14.43 \%)$ and 10 cases out of 10 (the 9 th and $10 \mathrm{th}$ foetal month). In other words, the above-mentioned union is completed in embryos of the 9 th foetal month. In 23 cases out of 24 in which the presphenoid unites with the crus anterior of the orbitosphenoid, the presphenoid is already united with the crus posterior of the orbitosphenoid except in one case where the presphenoid unites with the crus anterior of the orbitosphenoid in advance. Based on the above-mentioned findings, it may be concluded that the presphenoid unites earlier with the crus posterior of the orbitosphenoid than with the crus anterior of the orbitosphenoid. This union is bilaterally observed in 23 cases $(95.83 \pm 4.07 \%)$ out of 24 .

3. The union with the basisphenoid

The union between the main centers of the presphenoid and the basisphenoid begins in a $31.5 \mathrm{~cm}$ embryo. Not a single case under $28.5 \mathrm{~cm}$ shows this type of union. However, 1 cases out of $15(29.0$ $31.5 \mathrm{~cm})(6.66 \pm 6.64 \%), 6$ cases out of $12(32.0-40.0 \mathrm{~cm})(50.00 \pm 14.43 \%)$, and 10 cases out of 10 (the 9 th and 10th foetal month) (100.00\%) were recognized to have this type of union. In other words, the union is completed in the 9 th foetal month. This union was observed on both sides in all cases.

4. The union with the presphenoid on the counter side

The union between both sides of the presphenoid occurs in the following manner. First each side of the corporal, middle center approaches the median line. As the profound corporal, middle center on both sides unites with the same side of superficial main center, both 
sides of the main center unite ultimately with each other on the median line. As far as this type of union is concerned, in no case under $31.5 \mathrm{~cm}$ is the union seen. However, this union was observed in 3 cases out of $12(32.0-40.0 \mathrm{~cm})(25.00 \pm 12.53 \%)$, and 10 cases out of 10 (the 9 th and 10 th foetal month) (100.00\%). In other words, this type of union is completed in the 9 th foetal month.

Two medially placed foramina, a greater anterior opening and a smaller posterior opening, were formed by the union between the presphenoid and the basisphenoid. The posterior opening is reported as craniopharyngeal canal by S o k o low (1904), S c h la gin ha f e n (1907), S palteholz (1919) etc. These foramina are cartilaginous intervals in the dehydrated skull, while they are vacant in the sphenoid bone. The first formation of the foramina was made in an embryo of $34.0 \mathrm{~cm}$, inasmuch as they cannot be formed without first having a union between the presphenoid and the basisphenoid. These openings were completed in 3 cases out of $12(32.0-40.0 \mathrm{~cm})$ $(25.00 \pm 13.53 \%)$, and in 10 cases out of 10 (the 9 th and the 10 th foetal month) (100.00\%). In 3 embryos out of the $32.0-40.0 \mathrm{~cm}$ group (No. 323, No. 283 and No. 362) the anterior opening was of triangular shape, behind which lies the posterior opening, the size of a pin head. In 2 cases (No. 323 and No. 362) out of the above, the posterior opening is connected with the anterior opening by a thin duct, while in one case (No. 283) the anterior opening was separated from the posterior opening and formed two isolated openings. All cases of the 9 th and 10 th foetal month possess such openings and of these only a single case (No. 432) in which 2 openings were connected while the rest of the cases showed two separate.openings. The anterior opening in the 9 th and 10 th foetal month group showed a reduction in size and moreover the triangular shape changed to a round shape through an oval shape which ultimately became entirely closed leaving a pin point trace. On the other hand, the posterior opening, compared against the above-mentioned 3 cases in the other group showed no changes in size or in forms and stayed as big as a pin head. Further observations were made on the sphenoid bone of 4 infants (No. 447-28 days old, No. 365-2 months old, No. 3924 months old and No. 328-10 months old). In these infants the posterior opening was larger than the anterior opening in size with the exception of one case (No. 447). In the case of embryos the closed anterior opening was located on the surface of or at the anterior border of the tuberculum sellae, while the closed posterior opening was located at the posterior border of the tuberculum sel- 
lae. In the case of infants, in addition to the above, the closed posterior opening lies in the region of the completed basisphenoid, which may give the impression that the posterior opening originally existed in the basisphenoid.

As for the destiny of the ossific centers of the presphenoid, as a result of the afore-mentioned unions, the so-called "presphenoid" after birth of which borders are limbus sphenoidalis in front and tuberculum sellae behind is superficially formed by the main centers, the anterior, accessory centers, the posterior, accessory centers and the middle, accessory center of the presphenoid. The profound portion of the so-called "presphenoid" is formed by the corporal, middle centers of the presphenoid and especially the sphenoidal crest and rostrum are formed by the anterior part of the corporal, middle centers of the presphenoid, which projects forwards and creeps under the jugum sphenoidale forming the orbitosphenoids, which completely overlies the presphenoid superiorly.

\section{Discussion}

It is reported that at an early stage of development of the presphenoid up till the 3rd foetal month the orbitosphenoid remains a part of cartilago sphenoethmoidalis which is an united nodule of cartilage ( $\mathrm{Keibel}$ u. M a ll, 1910). As may be seen in picture of the above-mentioned cartilage at the base of the skull, the presphenoid may be considered as a part of cartilago sphenoethmoidalis. All workers agree that the ossification of the presphenoid takes place at the medial end of the optic canal. The number of the ossific centers of the presphenoid were reported as 2 pairs, 4 pieces by $\mathrm{H}$ a n n o ver (1880), and 1 pair, 2 pieces by Toldt (1882), S u tto $n$ (1885) and $S$ a p pey (1888). In the present paper the number of the ossific centers of the presphenoid were found to be 5 types, 9 pieces by the author. In other words, the presphenoid may be said to consist of poly-ossific centers rather than of mono-ossific centers. There is much controversy concerning the period of the ossification of the presphenoid. The earliest ossifying period described is at the 10 th week by In kster, while the latest period described is at the 3rd foetal month by $\mathrm{Hannover.} \mathrm{In} \mathrm{the} \mathrm{pre-}$ sent paper the earliest ossification of the presphenoid was found in an embryo of the beginning of the 4 th foetal month, which finding stands closest to $\mathrm{H}$ a $\mathrm{n} \mathrm{n}$ over's.

The period of the union between the ossific center of the pre- 
sphenoid and other ossific centers are reported to vary by other workers. It is generally reported that the union between the presphenoid and the orbitosphenoid, the basisphenoid and the counter side of the presphenoid fails to begin simulataneously, but differs according to corresponding centers. However, all workers agree that the earliest union occurs between the presphenoid and the orbitosphenoid. However, workers do not agree as to which of the basisphenoid and the counter side of the presphenoid the presphenoid unites first. According to I $\mathrm{nks}$ ter the presphenoid unites earlier with the other side of the presphenoid (the 6 th foetal month) than with the basisphenoid (the 7 th foetal month). According to $\mathrm{Keibel}$ u. Ma ll, the presphenoid unites with the basisphenoid (the 7 th and the 8 th foetal month) earlier than or at the same time with the counter side of the presphenoid (the 8 th foetal month). It was clarified by the present writer that the presphenoid first unites with the orbitosphenoid (at the beginning of the 5th foetal month), next with the basisphenoid (at the beginning of the 7 th foetal month), and finally with the counter side of the presphenoid (at the end of the $7 \mathrm{th}$ foetal). As a whole, the findings by the present writer are the closest to those by $\mathrm{Keibel} \mathrm{u}$. M a ll, as far as the unions of the ossific centers are concerned.

Two medially placed foramina between the presphenoid and the basisphenoid are reported by $L$ a $r e n c e$ and Inkster, even though their descriptions are brief without the details of the process of the formation, the changes of the forms and size. Moreover, the location of two openings described differs from that reported by the present writer. Hence, it might be said that new findings. were obtained concerning the process of the formation, the forms and the location of these openings.

\section{Conclusion}

I. The Ossific Centers

1. The presphenoid consists of many ossific centers, i. e., 5 types, 9 pieces: a pair of the main centers, a pair of the anterior, accessory centers, a pair of the posterior, accessory centers, a piece of the middle, accessory center and two pieces of corporal, middle center.

2. Of all types of ossific centers of the presphenoid, the first to appear is the main center, which was observed in an embryo of 
$18.0 \mathrm{~cm}$.

3. The ossific centers of the presphenoid vary remarkably in size and in the date of the appearance.

4. Of all types of ossific centers in the presphenoid, the main centers, the anterior, accessory centers appear in comparatively earlier foetal months, while the posterior, accessory centers and the corporal, middle centers appear in comparatively later foetal months.

5. Of all types of ossific centers in the presphenoid, the main center, the anterior, accessory center and the corporal, middle center were observed in all cases, while the rates of appearance of the posterior, accessory center and the middle, accessory center were extremely low, because of the defective formation of the ossific centers.

II. The Unions

1. The presphenoid unites first with the crus posterior of the orbitosphenoid in the 6 th foetal month, and with the crus anterior of the orbitosphenoid in the 6 th foetal month, and with the basisphenoid at the beginning of the 7 th foetal month, and ultimately with the other side of the presphenoid at the end of the 7 th foetal month.

2. The union between the presphenoid and the crus posterior of the orbitosphenoid was completed in an embryo of $32.0 \mathrm{~cm}$ and the union between the presphenoid and the crus anterior of the orbitosphenoid, the basisphenoid and the counter side of the presphenoid was completed in the 9 th foetal month.

3. The superficial portion of the presphenoid was formed by the main centers, the anterior, accessory centers, the posterior, accessory centers and the middle, accessory center, while the profound portion of the presphenoid was formed by the corporal, middle centers.

4. Two medially placed foramina between the presphenoid and the basisphenoid were observed; one foramen on the surface or at the anterior border of the tuberculim sellae, the other at the posterior border of the tuberculum sellae. These foramina were closed by the 10th month after birth.

\section{References}

1. Ha nnover, A.: Primordialbrusken og dens Forbening i det menneskelige Kranium, Det K.D. Videnskabernes Selekabs Skrifter, Kjöbenhavn 1880. im Bardele- 
ben'schen Handbuch der Anatomie des Menschen. 1896.

2. Inkster, R.G.: Osteology in Cunningham's text-book of anatomy edited by: Brash, J. C. Ninth Edition, 1951.

3. Ke i bel F.u. Mall F.P.: Handbuch der Entwicklungsgeschichte des Menschen. Erster Band. 1910.

4. Lawrence, : Osteology in Cunningham's text-book of antomy edited by R o b i n s o n, A. Fifth Edition. 1928.

5. Sappey, Ph. C.: Traité d'anatomie descriptive. 1888.

6. Schlag inhaufen, O.: Ein Canalis craniopharyngeus persistens an einem Menschenschädel und sein Vorkommen bei den Anthropoiden. Anat. Anz. Bd. 30, 1907.

7. Sokolow, P.: Der Canalis craniopharyngeus. Arch. f. Anat. u. Physiol., Anat. Abt. 1904.

8. Spalteholz, W.: Handatlas der Anatomie des Menschen. 1919.

9. Sutton, J.B.: On the relationship of the orbitosphenoid to the region pterion in the side wall of the skull. Journ. of Anat. and Physiol. 1884.

10. Toldt, C.: Die Entstehung und Ausbild. der Conchae sphenoidales beim Menschen. Lotos. Jhrb. f. Naturw. 1882.

\section{Explanation of Figures}

Fig. 2. Dehydrated skull of an embryo (No. 224, male, $22.0 \mathrm{~cm}$ ). A pair of main centers of the presphenoid are seen medial to the orbitosphenoids in pair.

Fig. 3. Dehydrated skull of an embryo (No. 332, female, $30.0 \mathrm{~cm}$ ). A pair of the anterior, accessory centers are seen dorsal to the main centers and near the crus anterior of the orbitosphenoid.

Fig. 4. Dehydrated skull of an embryo (No. 328 , female, $31.0 \mathrm{~cm}$ ). A pair of posterior, accessory centers are seen at the posterior, lateral end of the main centers.

Fig. 5. Dehydrated skull of an embryo (No. 371, male, $34.0 \mathrm{~cm}$ ). The middle, accessory center is seen on the median line, situated between both sides of the main centers.

Fig. 6. Dehydrated skull of an embryo (No. 301 , male, $36.0 \mathrm{~cm}$ ). The corporal, middle centers consisting of an anterior and a posterior center are seen on the median line. The former is column-formed, the latter is roundish with a split seen in between.

Fig. 7. Dehydrated skull of an embryo (No. 304, female, $26.0 \mathrm{~cm}$ ). The unior between the main centers of the presphenoid and the crus posterior of the orbitosphenoids is seen. On the left, the main center is apparantly united with the crus anterior of the orbitosphenoid, but actually is separated.

Fig. 8. Dehydrated skull of an embryo (No. 266, male, $26.5 \mathrm{~cm}$ ). A bony ring around the optic canal is bilaterally formed by the union between the main center of the presphenoid and both cruris of the orbitosphenoid.

Fig. 9. Dehydrated skull of an embryo (No. 323 , female, $34.0 \mathrm{~cm}$ ). The union between the main centers of the presphenoid and the basisphenoid is seen.

Fig. 10. Dehydrated skull of an embryo (No. 286, male, $40.0 \mathrm{~cm}$ ). Both sides of the presphenoid are united at the median line.

Fig. 11. Macerated skull of an embryo (No. 347, female, the 10th foetal month). Both sides of the anterior, accessory centers are about to unite at the median line. Under them the anterior portion of the corporal, middle centers penetrate through 
to form the sphenoidal crest and rostrum.

Fig. 12. Macerated skull of an embryo (No. 442, female, the 10 th foetal month). Both sides of the orbitosphenoid approach towards the median line to form the jugum sphenoidale. Laterally and behind it a pair of the anterior, accessory centers exist. The anterior portion of the corporal, middle center penetrates under the jugum sphenoidale and the anterior, accessory centers, ultimately forming the sphenoidal crest and rostrum.

Fig. 13. Dehydrated skull of an embryo (No. 362 , male, $40.0 \mathrm{~cm}$ ). The anterior foramen surrounded by the presphenoids and the basisphenoid show a triangular shape: the posterior foramen being the size of a pin head. These two openings are connected, being filled by cartilage.

Fig. 14. Macerated skull of an embryo (No. 449, female, the 9 th foetal month). The anterior opening is of triangular shape, while the posterior opening is a pinpoint. No connection is observed between the two openings.

Fig. 15. Macerated skull of an embryo (No. 432, male, the 10th foetal mnnth). The anterior foramen is of triangular shape, and the posterior opening is round. These two are connected by a thin slit.

Fig. 16. Macerated skull of an embryo (No. and sex unknown, the 10th foetal month). The anterior opening is oval, while the posterior is round. No connection is observed in between.

Fig. 17. Macerated skull of an infant (No. 365, sex unknown, the 2nd month after birth). Both openings are equally as big as a pin head owing to the enclosure.

Fig. 18. Macreated skull of an infant (No. 328, male, the 10th month after birth). Both openings are entirely closed, leaving a trace, the size of a pin-point. 
Plate I

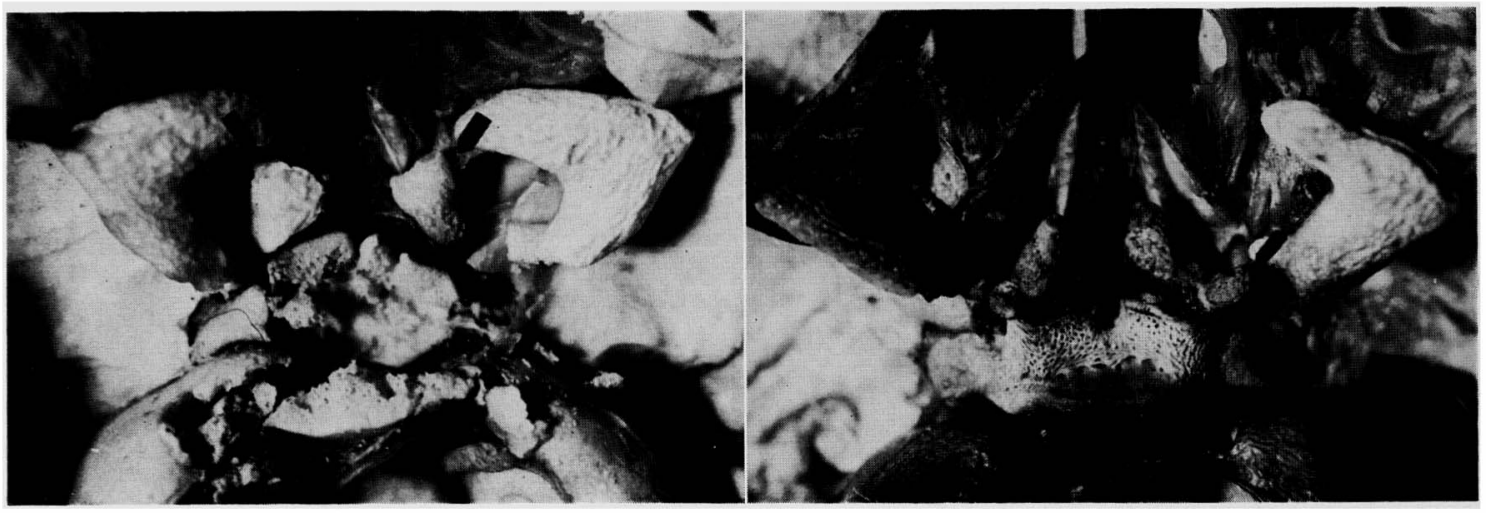

Fig. 2.

Fig. 4.

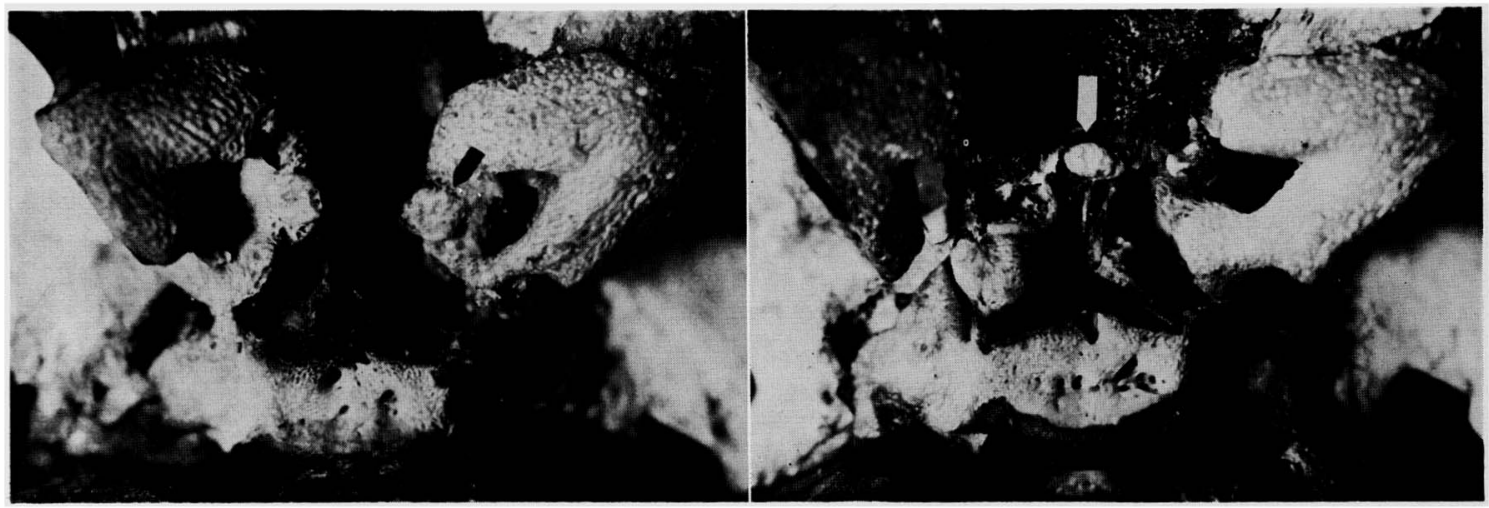

Fig. 3.

Fig. 5.

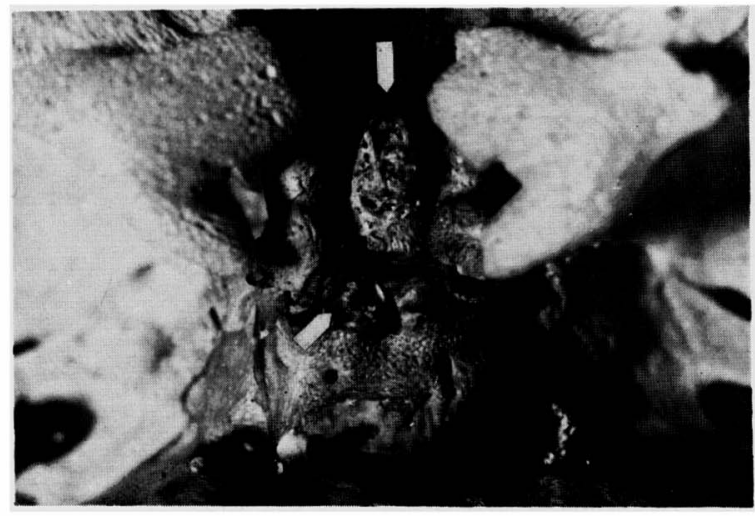

Fig. 6 .

G. Kodama 
Plate II

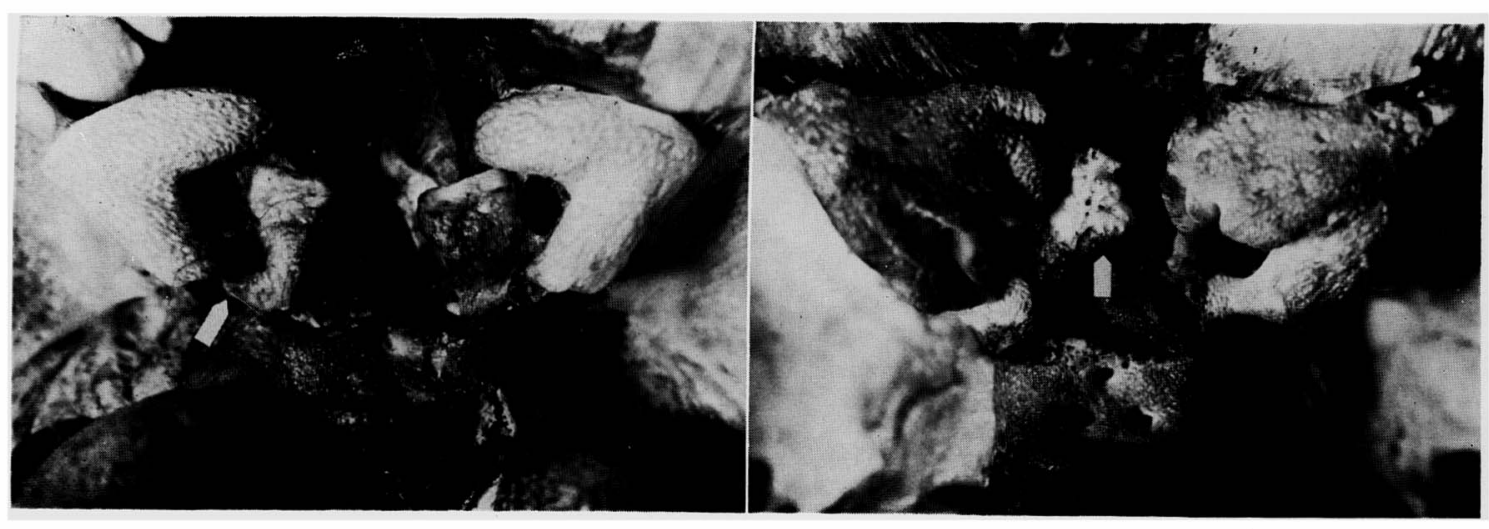

Fig. 7.

Fig. 10.

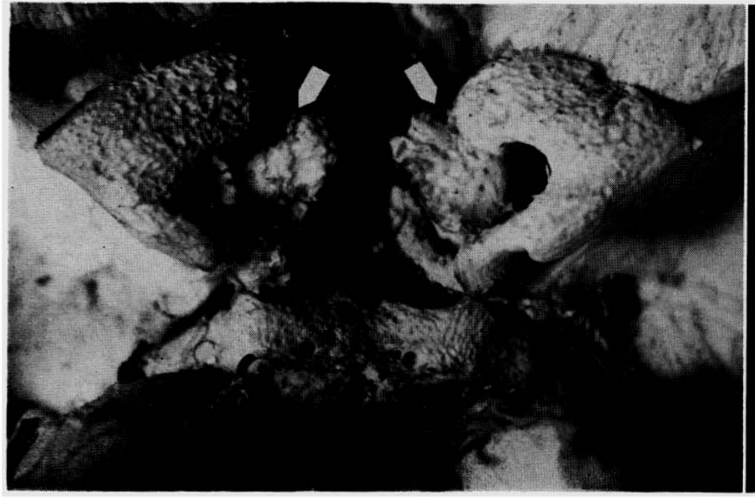

Fig. 8.

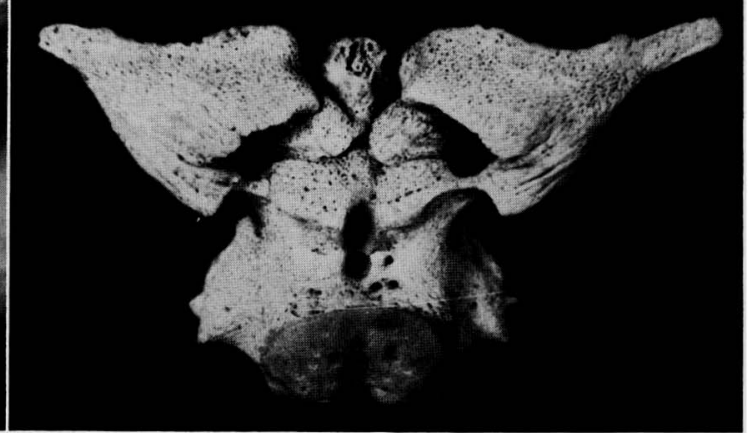

Fig. 11.

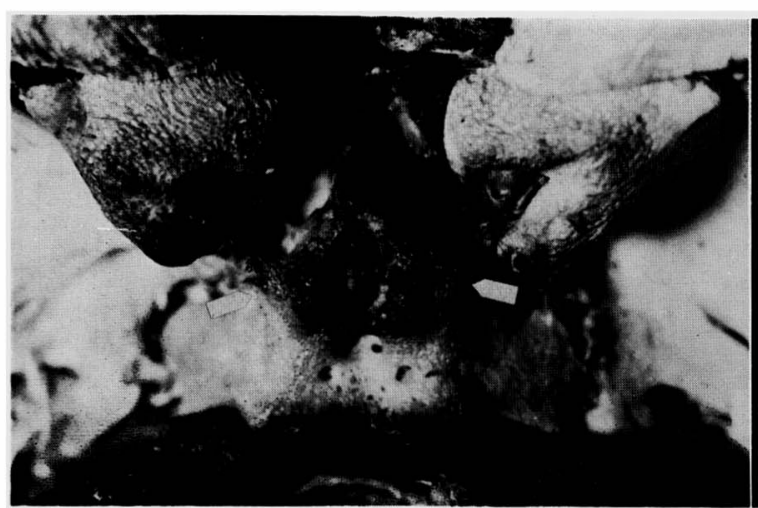

Fig. 9.

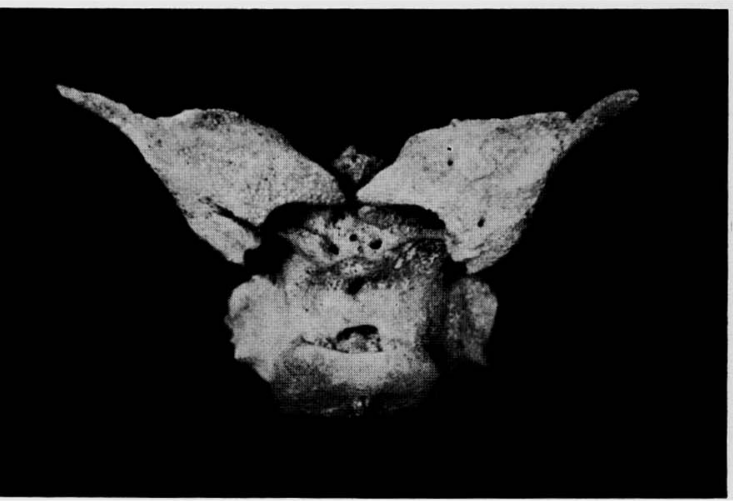

Fig. 12.

G. Kodama 
Plate III

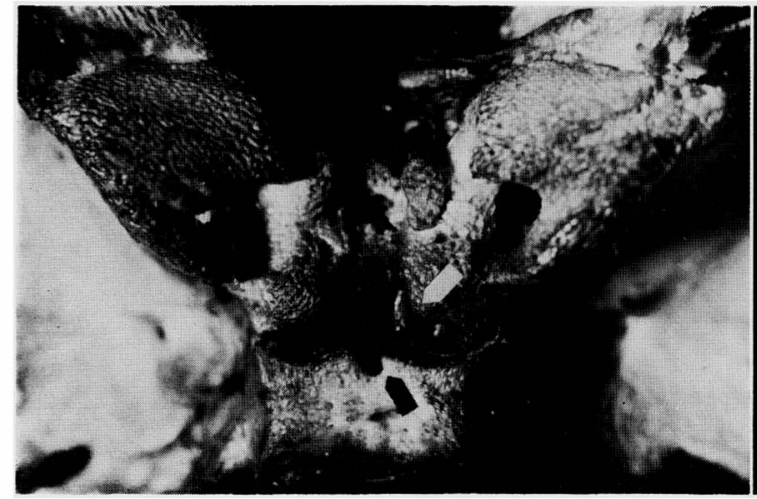

Fig. 13.

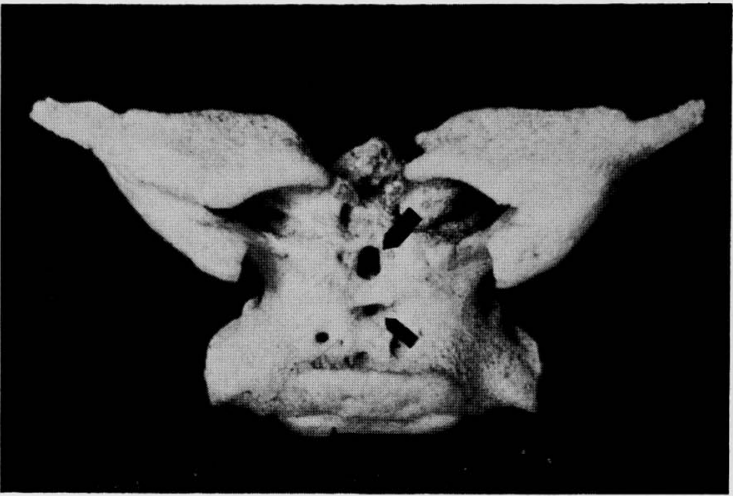

Fig. 16.

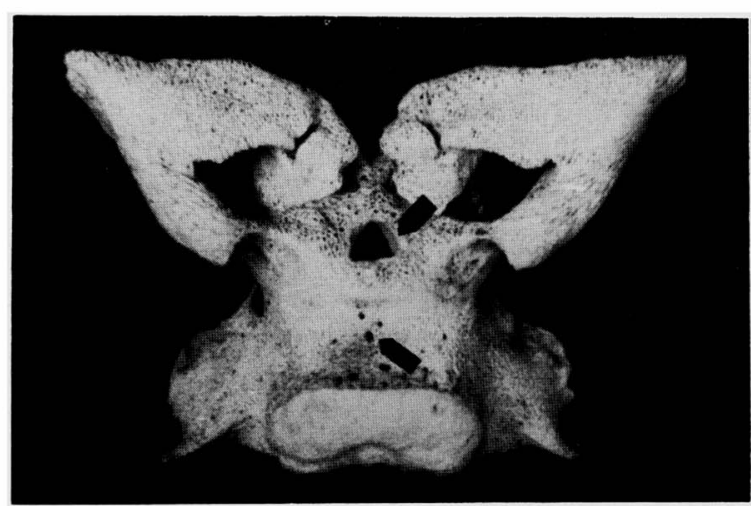

Fig. 14.

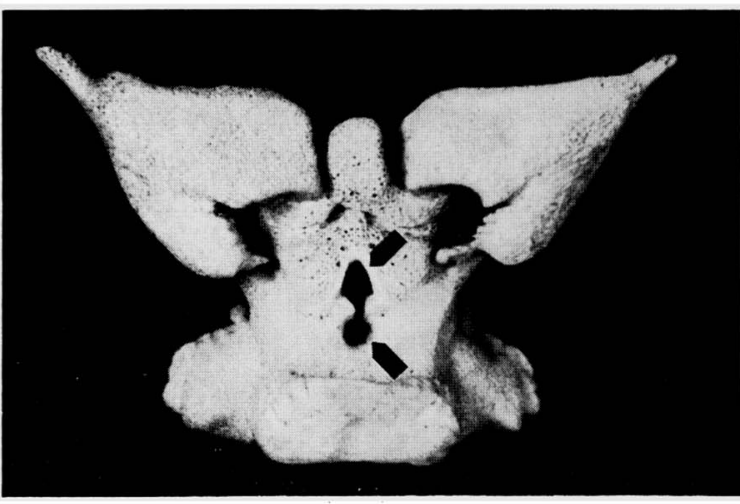

Fig. 15.

G. Kodama

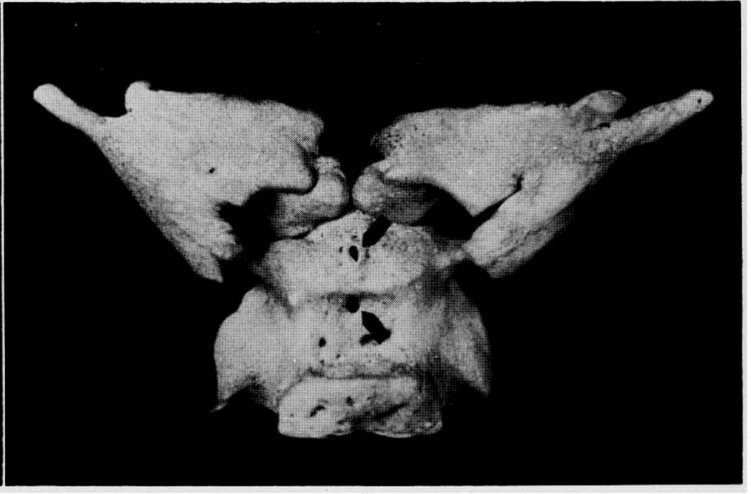

Fig. 17.

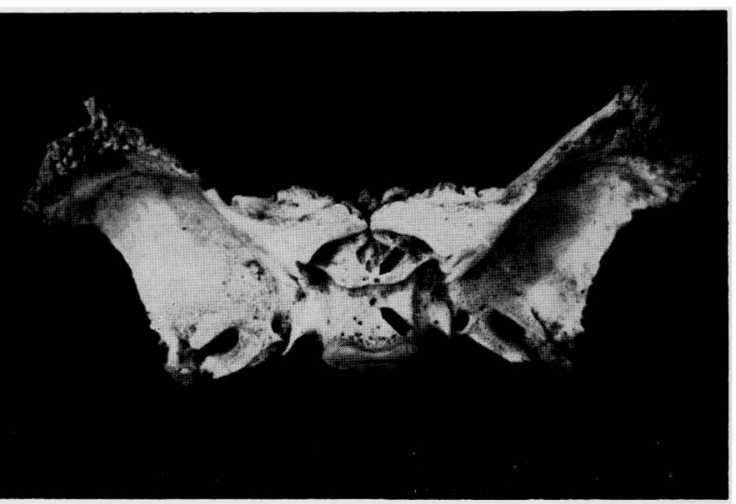

Fig. 18. 